\title{
Scales and mechanisms of marine hotspot formation
}

\author{
Elliott L. Hazen ${ }^{1,2, *}$, Robert M. Suryan ${ }^{3}$, Jarrod A. Santora $^{4,5}$, Steven J. Bograd ${ }^{1}$, \\ Yutaka Watanuki ${ }^{6}$, Rory P. Wilson ${ }^{7}$ \\ ${ }^{1}$ National Oceanic and Atmospheric Administration, Southwest Fisheries Science Center, Pacific Grove, California 93950, USA \\ ${ }^{2}$ Institute of Marine Sciences, University of California, Santa Cruz, 100 Shaffer Road, Santa Cruz, California 95060, USA \\ ${ }^{3}$ Oregon State University, Hatfield Marine Science Center, 2030 SE Marine Science Dr., Newport, Oregon 97365, USA \\ ${ }^{4}$ Farallon Institute for Advanced Ecosystem Research, 101 H Street, Suite Q, Petaluma, California 94952, USA \\ ${ }^{5}$ Center for Stock Assessment and Research, University of California Santa Cruz, 110 Shaffer Road, Santa Cruz, \\ California 95060, USA \\ ${ }^{6}$ Graduate School of Fisheries, Hokkaido University, Hakodate, Hokkaido 041-8611, Japan \\ ${ }^{7}$ Biosciences, College of Science, Swansea University, Singleton Park, Swansea SA2 8PP, UK
}

\begin{abstract}
Identifying areas of high species diversity and abundance is important for understanding ecological processes and conservation planning. These areas serve as foraging habitat or important breeding or settlement areas for multiple species, and are often termed 'hotspots'. Marine hotspots have distinct biophysical features that lead to their formation, persistence, and recurrence, and that make them important oases in oceanic seascapes. Building upon a session at the North Pacific Marine Science Organization (PICES), this Theme Section explores the scales and mechanisms underlying hotspot formation. Fundamentally, understanding the mechanisms of hotspot formation is important for determining how hotspots may shift relative to ocean features and climate change, which is a prerequisite for determining management priorities.
\end{abstract}

KEY WORDS: Hotspot - Ocean features - Aggregations - Bottom-up processes - Biodiversity · Marine conservation

Resale or republication not permitted without written consent of the publisher

\section{What is a biological hotspot?}

The term 'hotspot' is used with increased frequency in marine biology and conservation literature. The concept of a hotspot of biodiversity has a longer history in the terrestrial community, with Myers (1988) defining hotspots as areas featuring both high endemism and risk to habitat (Myers et al. 2000). These concepts translate well to more static marine habitats such as coral reefs and kelp forests, but are less easily applied to pelagic systems, where both boundaries and features are dynamic. Here, we build upon previous studies that have defined pelagic hotspots based on bathymetric variation (Dower \& Brodeur 2004) and ocean features in the North Pacific (Sydeman et al. 2006), to identify the biophysical mechanisms that result in hotspot formation. This requires defining the concept of a marine hotspot, particularly when it consists of mobile features.

We have taken a biophysical approach to defining marine hotspots, focusing on their ecological rather than their conservation importance. Understanding mechanisms that result in hotspot formation is critical to identify areas of high ecological importance and ultimately conservation concern. Hotspots in marine systems can be defined by (1) important life history areas for a particular species, (2) areas of high biodiversity and abundance of individuals, and (3) areas of important productivity, trophic transfer, and biophysical coupling (Dower \& Brodeur 2004, Sydeman et al. 2006, Santora \& Veit 2013, this Theme Section). Areas of high trophic transfer are of particular interest, because predictable and recurrent productivity hotspots often serve as the foundation of pelagic food 
webs. Fundamentally, hotspot formation operates across a suite of spatial and temporal scales (discussed in the next section; see Fig. 1).

Life-history hotspots are critical to a large proportion of a species or population, particularly at sensitive life history stages. Examples of life-history hotspots include spawning aggregations, juvenile settling habitat, and areas providing unique foraging resources. For example, bluefin tuna migrate across the Atlantic and regularly use the warm waters in the Gulf of Mexico to spawn (Teo et al. 2007), and grouper species form spawning aggregations in predictable regions (Beets \& Friedlander 1999, Sala et al. 2001, De Mitcheson et al. 2008). Current speed, eddy activity, or shelf break habitat within these regions may be important for larval dispersal or retention to maximize survival (Teo et al. 2007, Heyman \& Kjerfve 2008). Benthic habitats such as seagrass beds can serve as settlement areas for pelagic fish (Ford et al. 2010) and as foraging habitat for juvenile turtles (McClellan \& Read 2007, Casale et al. 2012). Foraging hotspots close to a breeding colony can support a large portion of each species' population while also serving as important areas of trophic energy transfer from the physical environment to phytoplankton to seabirds (Santora et al. 2012a).

At the broadest scales, biodiversity hotspots most frequently occur in upwelling systems, coral reef ecosystems, and along some continental shelves (Tittensor et al. 2010). Where tropical and temperate habitats meet, there are consistent peaks in oceanic predator biodiversity (Worm et al. 2003). The California Current and North Pacific transition zone stand out as particular high biodiversity and high use hotspots (Bograd et al. 2010, Block et al. 2011). Coral reefs often contain high biodiversity, as they provide important structure and habitat near coastlines surrounding tropical and sub-tropical waters (Roberts et al. 2002, Bellwood et al. 2004). High biodiversity allows multiple paths of trophic transfer buffering against wasp-waist dominance of marine food webs (Field et al. 2006, Cury et al. 2008).

Trophic transfer hotspots often translate biophysical processes across multiple trophic levels by supporting a suite of mid-trophic organisms and, in turn, their predators. These areas often have a large ecosystem effect even though they may only support a subset of a predator's population or may not be areas of highest biodiversity. Aggregations of mid-trophic species can be important hotspots for top predators that migrate large distances to optimize foraging opportunities (Cotte \& Simard 2005, Bailey et al. 2010). The mechanisms underly- ing trophic hotspots can include island/seamount wake effects (Johnston \& Read 2007, Morato et al. 2010), upwelling shadows (Nur et al. 2011, Wingfield et al. 2011, Pardo et al. 2013, this Theme Section), wind or eddy-driven upwelling (Croll et al. 2005, Atwood et al. 2010, Thorne \& Read 2013, this Theme Section), or bathymetric features (Croll et al. 2005, Gende \& Sigler 2006). Fundamentally, changes in these hotspots may have indirect consequences on ecosystem functioning that cascade through to top predators.

\section{Scales of hotspots}

Inherent to all studies of marine hotspots is the concept of scale - ecological phenomena interact at discrete and often multiple spatial and temporal scales. A Stommel diagram of hotspot mechanisms shows how processes vary across space and time, and for simplicity assumes that the scaling between time and space is linear (Fig. 1). However, meso- and finescale studies of aggregative responses among ocean physics, predators and prey have revealed complex non-linear interactions (Hunt \& Schneider 1987, Piatt 1990, Fauchald et al. 2000).

Research on the scale of physical and biological hotspots is often dictated by the sampling methodologies and technology employed. For example: (1) Satellite-based observations of ocean conditions offer the greatest flexibility by sampling broadly through space and time at fine to basin scales, but are limited to surface conditions and only sample up to a proxy for primary production in chlorophyll a (Palacios et al. 2006). (2) Satellite-tracking of vertebrate predators is dependent on the resolution of tracking devices (e.g. GPS, pop-up archival), the predators' movement, and initial tagging location, but offer exceptional insight into top predator behavior, distribution, and their use of multiple marine ecosystems (e.g. hotspot connectivity, residency: Block et al. 2011, Bailey et al. 2012, Hazen et al. 2012; tagging through the stages: Montevecchi et al. 2012). (3) Shipboard surveys employ a variety of discrete and continuous sampling devices (e.g. nets, acoustics, visual observations) to quantify vertical and horizontal dimensions of seascapes and preyscapes, simultaneously offering insight into hotspot mechanisms and metrics of biodiversity (Santora et al. 2010, 2012a, Sigler et al. 2012), but are expensive and highly influenced by weather conditions. Ultimately, the integration across multiple types of observations should help resolve spatio-temporal mismatches. 


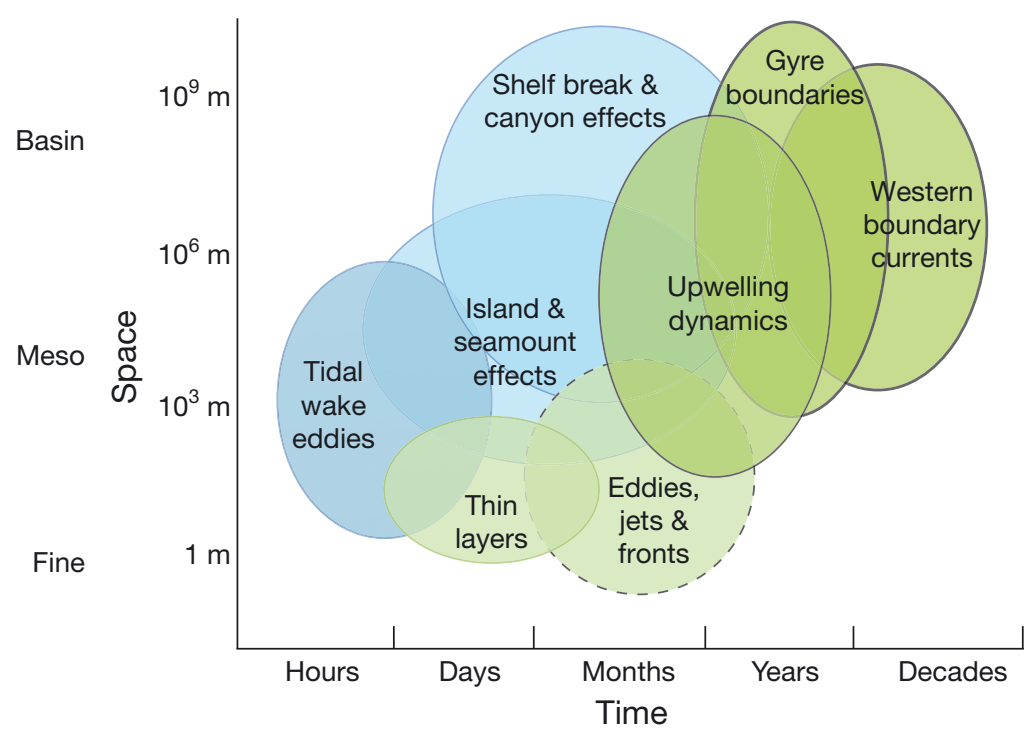

Fig. 1. Stommel diagram. Spatial scale (y-axis) plotted against temporal scale, focusing on persistence ( $x$-axis). Blue: bathymetric-driven hotspots; green: dynamic features that can move throughout the ocean. For example, upwelling dynamics operate on a temporal scale of days to months while tidally driven mixing lasts for hours. Black outline: features that are persistent throughout time rather than recurrent; dashed outline: features that are ephemeral and neither persistent nor recurrent

Studies of global hotspots, especially diversity/ richness hotspots, generally focus on relatively large grid size resolutions (e.g. $10 \mathrm{~km}$; months to decades) and may cover entire marine ecosystems (Tittensor et al. 2010, Block et al. 2011). This approach is useful for comparing biodiversity and risk across ecosystems and identifying important areas warranting finescale study (Halpern et al. 2008). Fine-scale research is necessary to elucidate mechanisms of biophysical hotspot formation and persistence and to understand critical species interactions within hotspots. At the global scale, most metrics for physical variability identified as underlying hotspots are proxies for key species interactions (Dawson et al. 2011, Hazen et al. 2013, Mokany et al. 2013).

Mesoscale structure (10 to $1000 \mathrm{~km}_{i}$ days to months) underlying physical and biological components of marine ecosystems often determine the strength and recurrence of marine hotspots, and can provide criteria for defining areas of high trophic transfer. Studies at fine spatial scales (1 to $10 \mathrm{~km}$ ) examining predator-prey-oceanography relationships are critical to describe the mechanisms that determine which mesoscale hotspots are formed and persist. For example, tidal flow and internal waves passing over topographic features in the Gulf of Maine result in dense aggregations of both krill and sand lance, which support seasonal foraging for hump- back and fin whales (Stevick et al. 2008, Hazen et al. 2009). Through the integrated assessment of physics, primary productivity, and secondary production, the coupling of fine and mesoscale sampling offers promising directions for studies of marine hotspots (Cury et al. 2008).

\section{Mechanisms of hotspot formation and persistence}

Physical processes leading to hotspot formation are varied, ranging from nutrient input to retention or aggregation of subsequent biological production. Mechanisms of nutrient input into the euphotic zone include freshwater run-off (Chase et al. 2007, Planquette et al. 2011), aeolian sources (Fan et al. 2006), and upwelling of deep, nutrient rich water (Meskhidze et al. 2007). Upwelling (or water column mixing) can be seasonal or episodic when wind driven; however, upwelling-enhanced productivity can also be highly persistent, especially when resulting from relatively static or cyclical processes, such as the interaction of the Equatorial Undercurrent meeting the western Galapagos Islands (Palacios et al. 2006) or small scale, tidally driven current interactions with bathymetric features within a bay (Drew et al. 2013, Thorne \& Read 2013, both in this Theme Section). Likewise, anticyclonic eddies that form in coastal regions and spin-off into or form in the oceanic domain can entrain or upwell macronutrients, leading to 'traveling' open ocean hotspots of productivity (Crawford et al. 2007) that are often utilized by upper trophic level predators (Ream et al. 2005).

Hotspots can be a function of biophysical aggregation where physical features such as shelf breaks or ocean fronts lead to increased densities of phytoplankton or zooplankton, or bottom-up processes, such as where increased nutrient levels lead to greater primary productivity, greater densities of grazers, and so on up to mid-trophic and top-level predators (Mann \& Lazier 1996, Genin 2004). Due to transport mechanisms and temporal lags, a foraging hotspot may not coincide with a region of enhanced primary productivity. In these cases, spatial discordance can result from downstream transport of prey, such as zooplankton for foraging birds (Hunt et al. 1998, Thorne \& Read 2013, this Theme Section). There are good examples of bathymetric features 
creating important aggregative habitat for species such as krill where they can reduce their exposure to currents while being close to foraging needs (Fiedler et al. 1998, Cotte \& Simard 2005, Santora et al. 2010, Santora et al. 2011). These aggregations then become important foraging features for large predators such as baleen whales that require high densities of prey to maximize their foraging efficiency and energetic demands (Cotte \& Simard 2005, Sigler et al. 2012). Top-down hotspots are rare, but facilitated foraging, where pelagic predators such as tuna force forage fish towards the surface and make them more available to seabirds, can result in higher biodiversity at pelagic hotspots (Maxwell \& Morgan 2013).

The spatial and temporal dynamics of marine hotspot occurrence and persistence is quite important, yet infrequently examined (but see Gende \& Sigler 2006, Sigler et al. 2012, Suryan et al. 2012, Santora \& Veit 2013, this Theme Section). Many investigations have focused on long-term averages (i.e. spatial climatologies) of physical and biological conditions to map hotspots, but the greatest challenges for research on pelagic hotspots require studies melding space and time to quantify persistence of hotspots. Quantifying their spatio-temporal persistence will require highly replicated observations to establish a baseline scale of variability and measure the frequency of anomalies (Suryan et al. 2012). Due to their ability to sample local to global spatial scales over days to years, satellite-based observations of ocean conditions offer the greatest opportunity to examine the spatio-temporal persistence of many marine hotspots (Palacios et al. 2006). Moored observatories (e.g. Neptune, Diemos, Mars), repeated glider transects, or regular surveys can allow enhanced temporal observations at marine hotspot locations ( $\mathrm{Bi}$ et al. 2007, Moustahfid et al. 2012).

\section{Contributions to the Theme Section}

This Theme Section arose out of a session at the 2011 Annual Meeting of the North Pacific Marine Science Organization (PICES). The session built upon previous efforts to identify hotspots in the North Pacific and examine the biophysical mechanisms that result in their formation (Dower \& Brodeur 2004, Sydeman et al. 2006). The session consisted of 19 (total) presentations and posters. This Theme Section contains 8 studies with topics ranging from hotspots of marine snow to migratory top predators.

Prairie et al. (2013) in a laboratory experiment demonstrated mechanisms by which particles can be temporarily retained when encountering density gradients. The density of the aggregate relative to the density of the bottom layer in the gradient is the primary determinant of the extent that marine snow will aggregate, thereby enhancing food web development at the boundary layer.

Boucher et al. (2013) used oceanographic and individual-based movement models to examine larval haddock dynamics in the Gulf of Maine. In good years, increased retention lead to hotspots of larval haddock on the bank but additional factors played a role in the magnitude of haddock recruitment in a given year.

Nishikawa et al. (2013) examined how water column characteristics lead to phytoplankton blooms in the western North Pacific that develop into important spawning habitat for Japanese sardine Sardinops melanostictus. A deeper mixed layer and higher phytoplankton density resulted in increased spawning habitat north of the Kuroshio.

Smith et al. (2013) examined how a hurricane passing through the Gulf of Mexico may have temporarily increased foraging hotspots for bottlenose dolphins. The decline in foraging habitat months after Hurricane Katrina suggests some hotspots, such as seagrass beds, may have been lost or disrupted by the hurricane.

Pardo et al. (2013) studied the role of environmental seasonality in a cetacean community within a small bay in the Gulf of California. Different species used the bay as the season progressed; periods of mixing and pycnocline shoaling resulted in increased habitat for blue whales and 2 dolphin species, while other whales were more common during periods of stratification.

Thorne et al. (2013) evaluated the biophysical processes that structure foraging habitat for phalaropes, a surface-feeding, planktivorous seabird in the Bay of Fundy. Their model indicates that copepods are physically upwelled and advected down current, highlighting the potential for spatial mismatch of lower trophic level food web processes and predator foraging.

Drew et al. (2013) used visual transect surveys to examine how foraging strategies of seabirds resulted in differential habitat use in Glacier Bay, Alaska. Bathymetric variability results in differential current speeds and consequently a high diversity of hotspot types in the bay; modeling approaches may help to understand the development of fine scale foraging behavior that has so far been difficult to quantify.

Santora \& Veit (2013) examined species richness and abundance in top predators to identify persistent 
hotspots near the Antarctic Peninsula. They identified 15 richness hotspots associated with either the Antarctic Circumpolar Current, major breeding colonies, or submarine canyons.

\section{Future directions}

To cross spatio-temporal boundaries, more synthetic approaches to hotspot research are necessary, such as combining Eulerian and Lagrangian measurements of hotspot dynamics. Combining tag-based movement data with shipboard surveys can provide information on behavioral ecology and biodiversity to address the suite of physical and ecological processes that result in formation and prolonged use of marine hotspots at multiple trophic levels (see Benoit-Bird et al. 2013). Future studies of biophysical hotspots should explicitly address the scale and scope of their defined hotspot so that syntheses and comparisons can be made across studies of disparate marine ecosystems (Santora et al. 2012b).

One category of marine hotspots that remains under-researched is the deep scattering layers (DSLs) of the open ocean, which are made up of a complex of species including fish, shrimp, jellies, and squid. DSLs have been observed at various depths around the world, yet little is known on their extent or variability (Barham 1963). They serve as a critical prey resource in otherwise oligotrophic ocean basins, so understanding the spatial and temporal distribution of DSL hotspots is critical (Benoit-Bird \& Au 2004). Recent studies in Monterey Bay have shown a high degree of temporal variability in distribution, both vertical and horizontal, and abundance seasonally, of DSL organisms (Urmy et al. 2012). Broad scale spatial patterns of deepwater fishes in the southern California Bight were recently described, with low oxygen levels proposed as a primary mechanism determining vertical distributions (Koslow et al. 2011).

An increasing number of studies focus on areas in the ocean that are important for conservation. The Global Ocean Biodiversity Initiative (GOBI) is an international organization working to define Ecological and Biologically Significant Areas (EBSAs) in the world's oceans (Williams et al. 2010). The clear identification of hotspots and the establishment of a 'hotspot repository' would ensure the effective study of hotspot mechanisms and persistence, and subsequently inform management and conservation efforts. Dynamic management has been proposed and even implemented in a few systems, but with ocean use projected to increase in the future, new tools are required to optimize ecological services and ecosystem functioning (Hobday et al. 2010, Dunn et al. 2011, Grantham et al. 2011, Ronconi et al. 2012). Examination of the overlap between human-use hotspots and the temporal persistence of ecological hotspots will enable real-time management approaches to allow human uses when hotspots are absent and protect habitats when hotspots are persistent.

\section{LITERATURE CITED}

Atwood E, Duffy-Anderson JT, Horne JK, Ladd C (2010) Influence of mesoscale eddies on ichthyoplankton assemblages in the Gulf of Alaska. Fish Oceanogr 19:493-507

Bailey H, Mate BR, Palacios DM, Irvine L, Bograd SJ, Costa DP (2010) Behavioural estimation of blue whale movements in the Northeast Pacific from state-space model analysis of satellite tracks. Endang Species Res 10:93-106

Bailey H, Benson SR, Shillinger GL, Bograd SJ and others (2012) Identification of distinct movement patterns in Pacific leatherback turtle populations influenced by ocean conditions. Ecol Appl 22:735-747

Barham EG (1963) Siphonophores and the deep scattering layer. Science 140:826-828

$>$ Beets J, Friedlander A (1999) Evaluation of a conservation strategy: a spawning aggregation closure for red hind, Epinephelus guttatus, in the U.S. Virgin Islands. Environ Biol Fishes 55:91-98

Bellwood DR, Hughes TP, Folke C, Nystrom M (2004) Confronting the coral reef crisis. Nature 429:827-833

Benoit-Bird KJ, Au WWL (2004) Diel migration dynamics of an island-associated sound-scattering layer. Deep-Sea Res I 51:707-719

Benoit-Bird KJ, Battaile BC, Heppell SA, Hoover B and others (2013) Prey patch patterns predict habitat use by top marine predators with diverse foraging strategies. PLoS ONE 8:e53348

Bi HS, Ruppel RE, Peterson WT (2007) Modeling the pelagic habitat of salmon off the Pacific Northwest (USA) coast using logistic regression. Mar Ecol Prog Ser 336:249-265

Block BA, Jonsen ID, Jorgensen SJ, Winship AJ and others (2011) Tracking apex marine predator movements in a dynamic ocean. Nature 475:86-90

Bograd SJ, Block BA, Costa DP, Godley BJ (2010) Biologging technologies: new tools for conservation. Introduction. Endang Species Res 10:1-7

Boucher JM, Chen C, Sun Y, Beardsley RC (2013) Effects of interannual environmental variability on the transport-retention dynamics in haddock Melanogrammus aeglefinus larvae on Georges Bank. Mar Ecol Prog Ser 487:201-215

Casale P, Broderick AC, Freggi D, Mencacci R, Fuller WJ, Godley BJ, Luschi P (2012) Long-term residence of juvenile loggerhead turtles to foraging grounds: a potential conservation hotspot in the Mediterranean. Aquat Conserv 22:144-154

Chase Z, Strutton PG, Hales B (2007) Iron links river runoff and shelf width to phytoplankton biomass along the U.S. West Coast. Geophys Res Lett 34LO4607, doi:10.1029/ 2006GL028069

Cotte C, Simard Y (2005) Formation of dense krill patches under tidal forcing at whale feeding hot spots in the St. Lawrence Estuary. Mar Ecol Prog Ser 288:199-210 
Crawford WR, Brickley PJ, Thomas AC (2007) Mesoscale eddies dominate surface phytoplankton in northern Gulf of Alaska. Prog Oceanogr 75:287-303

Croll DA, Marinovic B, Benson S, Chavez FP, Black N, Ternullo R, Tershy BR (2005) From wind to whales: trophic links in a coastal upwelling system. Mar Ecol Prog Ser 289:117-130

> Cury PM, Shin YJ, Planque B, Durant JM and others (2008) Ecosystem oceanography for global change in fisheries. Trends Ecol Evol 23:338-346

> Dawson TP, Jackson ST, House JI, Prentice IC, Mace GM (2011) Beyond predictions: biodiversity conservation in a changing climate. Science 332:53-58

> De Mitcheson YS, Cornish A, Domeier M, Colin PL, Russell M, Lindeman KC (2008) A global baseline for spawning aggregations of reef fishes. Conserv Biol 22:1233-1244

$>$ Dower JF, Brodeur RD (2004) The role of biophysical coupling in concentrating marine organisms around shallow topographies. J Mar Syst 50:1-2

$>$ Drew GS, Piatt JF, Hill DF (2013) Effects of currents and tides on a fine-scale use of marine bird habitats in a Southeast Alaska hotspot. Mar Ecol Prog Ser 487:275-286

$>$ Dunn DC, Boustany AM, Halpin PN (2011) Spatio-temporal management of fisheries to reduce by-catch and increase fishing selectivity. Fish Fish 12:110-119

Fan SM, Moxim WJ, Levy H II (2006) Aeolian input of bioavailable iron to the ocean. Geophys Res Lett 33: L07602, doi:10.1029/2005GL024852

Fauchald P, Erikstad KE, Skarsfjord H (2000) Scale-dependent predator-prey interactions: the hierarchical spatial distribution of seabirds and prey. Ecology 81:773-783

Fiedler PC, Reilly SB, Hewitt RP, Demer D and others (1998) Blue whale habitat and prey in the California Channel Islands. Deep-Sea Res II 45:1781-1801

Field JC, Francis RC, Aydin K (2006) Top-down modeling and bottom-up dynamics: linking a fisheries-based ecosystem model with climate. Prog Oceanogr 68:238-270

> Ford JR, Williams RJ, Fowler AM, Cox DR, Suthers IM (2010) Identifying critical estuarine seagrass habitat for settlement of coastally spawned fish. Mar Ecol Prog Ser 408:181-193

> Gende SM, Sigler MF (2006) Persistence of forage fish 'hot spots' and its association with foraging Steller sea lions (Eumetopias jubatus) in southeast Alaska. Deep-Sea Res II 53:432-441

> Genin A (2004) Bio-physical coupling in the formation of zooplankton and fish aggregations over abrupt topographies. J Mar Syst 50:3-20

Grantham HS, Game ET, Lombard AT, Hobday AJ and others (2011) Accommodating dynamic oceanographic processes and pelagic biodiversity in marine conservation planning. PLoS ONE 6:e16552

> Halpern BS, Walbridge S, Selkoe KA, Kappel CV and others (2008) A global map of human impact on marine ecosystems. Science 319:948-952

> Hazen EL, Friedlaender AS, Thompson MA, Ware CR, Weinrich MT, Halpin PN, Wiley DN (2009) Fine-scale prey aggregations and foraging ecology of humpback whales Megaptera novaeangliae. Mar Ecol Prog Ser 395: 75-89

- Hazen EL, Maxwell SM, Bailey H, Bograd SJ and others (2012) Ontogeny in marine tagging and tracking science: technologies and data gaps. Mar Ecol Prog Ser 457: 221-240

> Hazen EL, Jorgensen S, Rykaczewski RR, Bograd SJ and others (2012) Predicted habitat shifts of Pacific top predators in a changing climate. Nat Clim Change 3:234-238

Heyman WD, Kjerfve B (2008) Characterization of transient multi-species reef fish spawning aggregations at Gladden Spit, Belize. Bull Mar Sci 83:531-551

Hobday AJ, Hartog JR, Timmiss T, Fielding J (2010) Dynamic spatial zoning to manage southern bluefin tuna (Thunnus maccoyii) capture in a multi-species longline fishery. Fish Oceanogr 19:243-253

Hunt GL Jr, Schneider DC (1987) Scale-dependent processes in the physical and biological environment of marine birds. In: Croxall JP (ed) Seabirds: feeding ecology and role in marine ecosystems. Cambridge University Press, Cambridge

> Hunt GL Jr, Russell RW, Coyle KO, Weingartner T (1998) Comparative foraging ecology of planktivorous auklets in relation to ocean physics and prey availability. Mar Ecol Prog Ser 167:241-259

> Johnston DW, Read AJ (2007) Flow-field observations of a tidally driven island wake used by marine mammals in the Bay of Fundy, Canada. Fish Oceanogr 16:422-435

> Kobayashi DR, Cheng IJ, Parker DM, Polovina JJ, Kamezaki N, Balazs GH (2011) Loggerhead turtle (Caretta caretta) movement off the coast of Taiwan: characterization of a hotspot in the East China Sea and investigation of mesoscale eddies. ICES J Mar Sci 68:707-718

> Koslow JA, Goericke R, Lara-Lopez A, Watson W (2011) Impact of declining intermediate-water oxygen on deepwater fishes in the California Current. Mar Ecol Prog Ser 436:207-218

Mann KH, Lazier J (1996) Dynamics of marine ecosystems, Vol 389. Blackwell Science, Cambridge, MA

Maxwell SM, Morgan LE (2013) Foraging of seabirds on pelagic fishes: implications for management of pelagic marine protected areas. Mar Ecol Prog Ser 481:289-303

McClellan CM, Read AJ (2007) Complexity and variation in loggerhead sea turtle life history. Biol Lett 3:592-594

Meskhidze N, Nenes A, Chameides WL, Luo C, Mahowald N (2007) Atlantic Southern Ocean productivity: fertilization from above or below? Global Biogeochem Cycles 21: GB2006, doi:10.1029/2006GB002711

Mokany K, Harwood TD, Ferrier S (2013) Comparing habitat configuration strategies for retaining biodiversity under climate change. J Appl Ecol 50:519-527

> Montevecchi WA, Hedd A, Tranquilla LM, Fifield DA and others (2012) Tracking seabirds to identify ecologically important and high risk marine areas in the western North Atlantic. Biol Conserv 156:62-71

Morato T, Hoyle SD, Allain V, Nicol SJ (2010) Seamounts are hotspots of pelagic biodiversity in the open ocean. Proc Natl Acad Sci USA 107:9707-9711

Moustahfid H, Jech MM, Weise MJ, Horne JK, O'Dor R, Alexander C (2012) Advancing 'bio' sensor integration with Ocean Observing Systems to support ecosystem based approaches. Proc Oceans 2012. IEEE, New York, NY

Myers N (1988) Threatened biotas: 'hotspots' in tropical forests. Environmentalist 8:187-208

> Myers N, Mittermeier RA, Mittermeier CG, da Fonseca GAB, Kent J (2000) Biodiversity hotspots for conservation priorities. Nature 403:853-858

> Nishikawa H, Ichiro Y, Komatsu K, Sasaki H, Sasai Y, Setou T, Shimuzu M (2013) Winter mixed layer depth and spring bloom along the Kuroshio front: implications for the Japanese sardine stock. Mar Ecol Prog Ser 487: 217-229 
Nur N, Jahncke J, Herzog MP, Howar J and others (2011) Where the wild things are: predicting hotspots of seabird aggregations in the California Current System. Ecol Appl 21:2241-2257

Palacios DM, Bograd SJ, Foley DG, Schwing FB (2006) Oceanographic characteristics of biological hot spots in the North Pacific: a remote sensing perspective. DeepSea Res II 53:250-269

Pardo MA, Silverberg N, Gendron D, Beier E, Palacios DM (2013) Role of environmental seasonality in the turnover of a cetacean community in the southwestern Gulf of California. Mar Ecol Prog Ser 487:245-260

Piatt JF (1990) The aggregative response of common murres and Atlantic puffins to schools of capelin. Stud Avian Biol $14: 36-51$

Planquette H, Sanders RR, Statham PJ, Morris PJ, Fones GR (2011) Fluxes of particulate iron from the upper ocean around the Crozet Islands: A naturally iron-fertilized environment in the Southern Ocean. Global Biogeochem Cycles 25:GB2011, doi:10.1029/2010GB003789

Prairie JC, Ziervogel K, Arnosti C, Camassa R, Falcon C, Khatri S, McLaughlin RM, White BL, Yu S (2013) Delayed settling of marine snow at sharp density transitions driven by fluid entrainment and diffusion-limited retention. Mar Ecol Prog Ser 487:185-199

Ream RR, Sterling JT, Loughlin TR (2005) Oceanographic features related to northern fur seal migratory movements. Deep-Sea Res II 52:823-843

Roberts CM, McClean CJ, Veron JEN, Hawkins JP and others (2002) Marine biodiversity hotspots and conservation priorities for tropical reefs. Science 295:1280-1284

Ronconi RA, Lascelles BG, Langham GM, Reid JB, Oro D (2012) The role of seabirds in Marine Protected Area identification, delineation, and monitoring: introduction and synthesis. Biol Conserv 156:1-4

Sala E, Ballesteros E, Starr RM (2001) Rapid decline of Nassau grouper spawning aggregations in Belize: fishery management and conservation needs. Fisheries 26: 23-30

Santora JA, Veit RR (2013) Spatio-temporal persistence of top predator hotspots near the Antarctic Peninsula. Mar Ecol Prog Ser 487:287-304

Santora JA, Reiss CS, Loeb VJ, Veit RR (2010) Spatial association between hotspots of baleen whales and demographic patterns of Antarctic krill Euphausia superba suggests size-dependent predation. Mar Ecol Prog Ser 405:255-269

Santora JA, Sydeman WJ, Schroeder ID, Wells BK, Field JC (2011) Mesoscale structure and oceanographic determinants of krill hotspots in the California Current: implications for trophic transfer and conservation. Prog Oceanogr 91:397-409
Santora JA, Field JC, Schroeder ID, Sakuma KM, Wells BK, Sydeman WJ (2012a) Spatial ecology of krill, micronekton and top predators in the central California Current: Implications for defining ecologically important areas. Prog Oceanogr 106:154-174

Santora JA, Sydeman WJ, Schroeder ID, Reiss CS and others (2012b) Krill space: a comparative assessment of mesoscale structuring in polar and temperate marine ecosystems. ICES J Mar Sci 69:1317-1327

Sigler MF, Kuletz KJ, Ressler PH, Friday NA, Wilson CD, Zerbini AN (2012) Marine predators and persistent prey in the southeast Bering Sea. Deep-Sea Res II 65-70: 292-303

Smith CE, Hurley BJ, Toms CN, Mackey AD, Solangi M, Kuczaj SA II (2013) Hurricane impacts on the foraging patterns of bottlenose dolphins Tursiops truncatus in Mississippi Sound. Mar Ecol Prog Ser 487:231-244

> Stevick PT, Incze LS, Kraus SD, Rosen S, Wolff N, Baukus A (2008) Trophic relationships and oceanography on and around a small offshore bank. Mar Ecol Prog Ser 363: 15-28

Suryan RM, Santora JA, Sydeman WJ (2012) New approach for using remotely sensed chlorophyll a to identify seabird hotspots. Mar Ecol Prog Ser 451:213-225

> Sydeman WJ, Brodeur RD, Grimes CB, Bychkov AS, McKinnell S (2006) Marine habitat 'hotspots' and their use by migratory species and top predators in the North Pacific Ocean: Introduction. Deep-Sea Res II 53:247-249

Teo SH, Boustany A, Block B (2007) Oceanographic preferences of Atlantic bluefin tuna, Thunnus thynnus, on their Gulf of Mexico breeding grounds. Mar Biol 152: 1105-1119

> Thorne LH, Read AJ (2013) Fine-scale biophysical interactions drive prey availability at a migratory stopover site for Phalaropus spp. in the Bay of Fundy, Canada. Mar Ecol Prog Ser 487:261-273

Tittensor DP, Mora C, Jetz W, Lotze HK, Ricard D, Vanden Berghe E, Worm B (2010) Global patterns and predictors of marine biodiversity across taxa. Nature 466: 1098-1107

Urmy SS, Horne JK, Barbee DH (2012) Measuring the vertical distributional variability of pelagic fauna in Monterey Bay. ICES J Mar Sci 69:184-196

Williams MJ, Ausubel J, Poiner I, Garcia SM and others (2010) Making marine life count: a new baseline for policy. PLoS Biol 8:e1000531

> Wingfield DK, Peckham SH, Foley DG, Palacios DM and others (2011) The making of a productivity hotspot in the coastal ocean. PLoS ONE 6:e27874

> Worm B, Lotze HK, Myers RA (2003) Predator diversity hotspots in the blue ocean. Proc Natl Acad Sci USA 100: 9884-9888 